\title{
Duration of environmental therapy as a factor in correction of emotional-personality sphere of addicts
}

\author{
Irina Skirtach ${ }^{1,2}$ and Svetlana Kuzenko, ${ }^{2, *}$ \\ ${ }^{1}$ Don State Technical University, Gagarin Sq., 1, Rostov-on-Don, 344000, Russia \\ ${ }^{2}$ Southern Federal University, Bolshaya Sadovaya str., 105/42, Rostov-on-Don, 344006, Russia
}

\begin{abstract}
The current state of alcoholism, based on the achievements of neurosciences, indicates that it is a multifactorial disorder, in the development of which, although biological predictors play an important role, predisposing psychological characteristics are no less important. That is why the need for an integrated approach to the rehabilitation of addicts is obvious. The use of art therapy in the work with addicts is quite common, but its effectiveness, optimal duration, features of its influence on the dynamics of indicators of strong-willed self-control, aggressiveness, and self-assessment of alcohol abusers are not studied enough. This paper presents the results of a study conducted on the basis of "Reshenie" rehabilitation center, 48 patients who are being treated for alcohol addiction took part in it. The people were divided into experimental and control groups. The standard rehabilitation program of the center for the experimental group was supplemented by a specially developed art-therapeutic complex, the control group received only a basic rehabilitation course. The research shows that the inclusion of art therapy in rehabilitation significantly increases the indicators of positive dynamics of strong-willed self-regulation of behavior in general, the dynamics of self-assessment indicators and negative dynamics of indicators and forms of aggressive behavior in the experimental group. It is shown that in order to obtain a remarkable effect from the rehabilitation program using art therapy methods in correcting the ability to control behavior, strong-willed control, inadequately inflated selfassessment, the duration of the art therapy program must be at least 8 weeks.
\end{abstract}

\section{Introduction}

Currently, the problem of addiction, particularly chemical, is of an acute social nature. According to the official statistics, the prevalence of this disease among the population tends to decline in recent years, but still in Russia, the average number of people with chemical addiction registered in medical and preventive organizations is $1,131.9$ per 100,000 people of the population, in some remote regions the figure reaches 3431.2 people [1]. There are several times more people with chemical addiction who are not registered. According to the classical definition, addictive behavior is a special type of destructive behavior that is

\footnotetext{
* Corresponding author: limpopo-is@yandex.ru
} 
expressed in the intention to escape from reality through a special change of the mental state. Chemicals and/or various objects are selected as means of changing mental state. There are several approaches to classify types of addictive behavior. The most used classification of addiction is a division into two forms: chemical and non-chemical; the latter, in its turn, includes many kinds. Alcoholism is a type of chemical addiction. According to the International Statistical Classification of Diseases (ICD-11), alcoholism is qualified as mental and behavioral disorders due to consumption of psychoactive substances or addictive behavior.

Alcohol addiction (alcoholism) is a progredient disease resulting from the prolonged, regular intake of alcoholic drinks for physical pleasure, characterized by three leading manifestations: changes in alcohol tolerance, the presence of craving for alcohol, withdrawal symptoms (a complex of symptoms of mental, somatovegetative and neurological disorders) upon termination of alcohol intake. It is accompanied by the formation of addiction, that is, a compulsive craving for alcohol consumption, the inability to refuse it with the progressive development of persistent, often irreversible, somatic, and neurological disorders, as well as mental and personal degradation [2]. In case of alcoholism, the restructuring of the personality structure progresses, and it manifests in the sharpening of premorbid typological personality traits and the growth of disharmony in the emotional-volitional sphere [3].

Hoffmann A.G. [2] indicates that long-term alcohol consumption results in the formation of psychopathy-like disorders, including scarcity of interests, prominent social maladaptation, moral and ethical decline and decrease of activeness, which, nevertheless, can be partially or completely reduced in case of prolonged cessation of alcohol consumption. According to the observations of A.G. Hoffmann, alcohol degradation of personality is characterized by persistent psychopathic disorders with insensitivity, gross cynicism, cruel aggression, deceitfulness, annoyance, persistent rent settings.

Berezin S.V. et al. [4] attribute low resistance to frustration and stress, predominance in the activities of hedonistic attitudes and motives, aggressiveness, perfectionism in actions, an external locus of control, reflecting the tendency to shift responsibility for their lives and behavior to other people and external circumstances, readiness for asocial ways of satisfying needs for psychological features of addictive people.

Korolenko Ts. P. and Dmitrieva N.V. [5] note that alcoholic addicts have emotional regulation of behavior dominating the rational, and they can be characterized by such features as malevolence, vengeance, envy, mood instability, dysphoria, euphoria, deceit, depressiveness, paroxysmally colored behavior.

Bratus B.S. [6] indicates that in case of alcoholism, the decay of the personality manifests itself primarily in the destruction of the motivational sphere, in particular, the hierarchy of values. In case of marked alcoholism, the so-called "motive shift to the target" occurs. The leading motive is the motive for changing consciousness using alcohol, which becomes a semantic personal motive and enters the "core of personality" of an addict. Alcohol consumption becomes an independent activity, and all other actions are auxiliary, subordinate to the main motive (changing consciousness using alcohol). According to Bratus B. S., such a change in the previous hierarchy of motives and needs (dominance of the need for alcohol) means changes of the personality structure of an addict.

Significantly, affective disorders are leading among other mental disorders in case of alcohol addiction and negatively affect the disease prognosis.

Kozhinova T. A. [3] indicates during a pathopsychological examination that addicts have low self-esteem, sense of unfulfillment, disbelief in possibilities, and veiled guilt.

According to Zentsova N. I. [7], the personal feature of people with chemical addiction, including alcohol, is manipulative behavior, which can be the result of low self-esteem, and fear of trusting relationships with people. According to her study, manipulative behavior can be adjusted using art therapy methods. 
Alcoholism is a serious medical and social problem, as it often results in disability, early death, personal degradation, interpersonal disorders, and it is the cause of serious worries of family members and close friends, suppress the cultural, socio-economic, psychological development of society $[8,9]$. All this is aggravated by the high availability of alcohol and the specific culture of consumption of alcoholic beverages, typical for Russian population and determined by the lack of a developed leisure industry for the general masses of the population.

Addiction is a chronic and recurrent disease, its main characteristic feature is the loss of control over the use of psychoactive substances (PAS), despite the negative consequences for life [10]. At the same time, the modern view on the problem is that addiction can be considered as a neuroplastic disorder determined by the consumption of PAS which provoke the impaired adequate functioning of many areas of the brain involved in providing cognitive functions, emotional state, adaptive behavior. However, the plasticity of the brain gives an opportunity to recover, but this requires the rejection of PAS. This refusal requires essential internal resources, self-confidence, control of own impulses, the ability to establish adequate interaction with other people, excluding the intake of PAS. The methods of medicine cannot solve this task completely, so the treatment of addictions cannot be presented without an appropriate psychological rehabilitation program aimed at the formation of internal resources. The scientists have been interested in non-pharmocological rehabilitation methods for a long time, but the increase in the number of methods and approaches requires empirical confirmation of the possibilities of applied psychological rehabilitation techniques. Assistance in obtaining a resource state can be provided through ecological enrichment of the environment [11], physical exercises [12], artistic and music therapy [13], meditative practices aimed at increasing the level of consciousness [14].

Art therapy for people with chemical addiction has advantages over other types of psychotherapy. In the process of art therapy, protective mechanisms can be avoided. Holt E.S. and Kaiser H.D. showed that art therapy helps addicts to express their emotions, investigate the connections between thoughts, feelings and behavior associated with substance consumption, the process of creating artworks activates thinking processes and memory [15]. Aletraris L. et al. [74] states that art and music therapy contribute to the treatment of addictions, but have different effects on different groups of patients, and indicate its effects such as reducing the denial of addiction and resistance and increasing motivation to treat alcoholism, stimulating and improving communication, encouraging patients to change [13]. Kopytin A. I. and Bogachev O.V. [16] proved that art therapy methods have not only certain potential, but also definite advantages in treatment and rehabilitation of people with chemical addictions. Compared to verbal psychotherapy sessions, art therapy provides an opportunity for non-verbal disclosure of feelings, facilitates the disclosure of the patient's inner world, provides a higher level of safety and comfort during classes. Zentsova N. I. [7] proved the effectiveness of visual art therapy, sand therapy and fairy tale therapy in working with addictive patients undergoing rehabilitation.

Nowadays, there are several definitions of art therapy, which similarly identify it as an interdisciplinary phenomenon, combining, first of all, art and psychology, as well as incorporating the achievements of medicine, sociology, cultural studies, pedagogy and other disciplines [17]. According to existing definitions, art therapy is:

- one of the directions of therapy that uses the creativity of patients as a factor of therapeutic and preventive effect, relying predominantly on one of the modalities, with the help of which clients creatively express themselves - fine arts, music, movement and dance or theatrics;

- a set of techniques of psychological influence and study of the inner world of the personality through artistic expression and various forms of creative activity;

- a form of expressive therapy that uses the creative process of creating works of art to 
improve the physical, mental and emotional well-being of a person;

- method of development and change of conscious and unconscious aspects of personality psyche by means of various forms and types of art [17];

- conscious use of creativity in order to satisfy psychological and emotional needs and increase self-consciousness, combining traditional theory and methods of psychotherapy with understanding of psychological aspects of the creative process [18].

It has been proved that the art-therapeutic process contributes to the prevention of neurosis-like personality states, the elaboration and outpouring of negative emotions, internal contradictions, helps to increase the level of awareness of one's feelings, take control of them which provides relaxation, relieving of mental tension, increasing of self-esteem [19], helps with interpreting displaced experiences, accepting one's feelings and experiences [16]. Moreover, art therapy is effective in working with people experiencing crisis conditions, in correcting the consequences of psychotraumatic stress, therapy of mental disorders [20, 21], in the medical and psychosocial rehabilitation of mental patients [22, 23]. All these problems intensify the personality alcoholization. According to the Resolution of the Russian ArtTherapeutic Association, art therapy can be successfully applied for treatment and prevention of various diseases, correction of psychosocial maladaptation and various behavioral disorders, achievement of higher quality of life and development of human potential [16]. All this makes it possible to use art therapy methods in working with patients suffering from different forms of addiction successfully $[15,16,18,19$, etc.].

The main goal of art therapy is to harmonize the internal state of the client, that is, to restore his/her ability to find the optimal condition which contributes to improving life and establishing balance [17].

It is necessary to emphasize such a characteristic feature of art therapy as resourcefulness. This is predetermined by the fact that the method of psychotherapeutic effect in art therapy contributes to the expansion of patient's experience, avoiding daily living of the patient [24]. The development of the creative potential of the individual, being not the main goal of therapy, but only a desirable positive side effect, becomes an absolute resource for the present and future life of the patient by forming the ability to find new creative approaches to understanding everyday problems and solving difficult situations that everyone inevitably encounters.

The main targets of art therapy during the work with patients with alcohol addiction will be the correction of disorders in the emotional sphere, the correction of strong-willed control and self-esteem, as well as the formation of skills of adaptive behavior, based on internal resources.

\section{Methods}

\subsection{Participants}

The study was conducted on the basis of the Rostov center for the treatment of drug addiction and alcoholism "Reshenie". There were 48 patients with the second stage of alcoholic addiction, who voluntary participated in the research (37 men and 11 women; their average age is $32.3 \pm 5.1$ years old). 24 people were the experimental group and 24 people - the control group. Age, sex and nosological composition were equalized.

The study included respondents without any mental illness and prominent somatic pathologies. Preliminary complete suppression of the manifestations of withdrawal syndrome was essential for including the respondent in the program. The study was conducted from May 2019 to May 2020. 


\subsection{Methods and procedure}

The study included three main steps:

Stage 1 is a primary psychodiagnostic study. At this stage, primary diagnostics of personal characteristics, strong-willed self-control, aggressiveness and self-esteem of respondents were carried out.

Stage 2 is the development and testing of a rehabilitation program using art therapy methods.

Patients of the experimental group were included in art therapy. Patients of the control groups underwent the usual course of rehabilitation without using art therapy methods.

The methodological basis of the art-therapeutic program was an approach to the rehabilitation of people addictive to surfactants using the methods of art therapy of Zentsova N.I. [7], recommendations for arranging group art therapy of Kiseleva M.V. [25].

The aim of the program is to correct the negative psychological characteristics of patients with alcohol addiction.

Tasks:

1) increase of the motivation to give up PAS.

2) reduction of emotional tension.

3) development of communicative personality traits (development of sociability, diplomacy, reduction of suspicion and conformism).

4) development of adequate self-esteem.

5) reduction of the level of aggressiveness and hostility.

6) development of strong-willed regulation of behavior and emotions.

The form of classes was group art therapy. Arrangement of the group: classes were held in groups of 8 people. All groups had the same content of classes. Duration: classes were held 2 times a week for 8 weeks. Duration of the class was from 1.5 to 2 hours. There were 16 classes in total.

Group class structure:

1. Setting up the contact between group members.

2. Explaining the task and its individual completion.

3. Demonstration of result, analysis, group discussion (not less than $60 \%$ of time of a meeting).

4. Summing up, feedback.

Methods:

1) Drawing techniques.

2) Sculpturing.

3) Collage.

4) Performance.

Due to low self-esteem and self-doubt, at the initial stages of art therapy, patients were given easier tasks available for completion, which was aimed at preventing the formation of a negative attitude to art therapy [26].

At this stage, after 4 weeks of the rehabilitation program, all groups underwent repeated testing of the investigated indicators.

Stage 3 is the final psychodiagnostic study and data processing, evaluation of the effectiveness of art therapy methods in correcting the investigated indicators, study of differences in the effect of art therapy depending on its duration (4 weeks and 8 weeks).

The following methods were used in the study:

1). Psychological testing: a questionnaire of strong-willed self-control (Zverkov L. G., Eidman E.V.); Budassi S.A. self-esteem methodology; methodology for diagnosing 
indicators and forms of aggression by Bass A. and Darka A. (standardization by Hwan A. A., Zaitsev Yu. A. and Kuznetsova Yu. A.).

2). Statistical methods of data processing: ANOVA variance analysis with repeated measurements, Fischer angular transformation criterion.

\section{Results}

The dynamics of psychological features of people with PAS addiction after the use of art therapy methods was studied on the basis of a comparison of the initial data with the results after 4 weeks and 8 weeks after the start of art therapy, which allowed not only to assess the effectiveness of the developed authorial program in working with patients with alcohol addiction, but also to identify the effects of art therapy depending on its duration.

During the examination of the features of self-esteem in patient groups, the prevalence of its levels (the number of patients with different levels of self-esteem) was analyzed, while too high and too low self-esteem by neurotic type indicated its impairment. Method average index did not reflect the adequacy of self-esteem and its impairment of the respondents (see Ошибка! Источник ссылки не найден.).

Primary analysis of the division of self-esteem study results showed that too low selfesteem by neurotic type is the most common one. This level of self-esteem was identified in $36 \%$ of addicts.

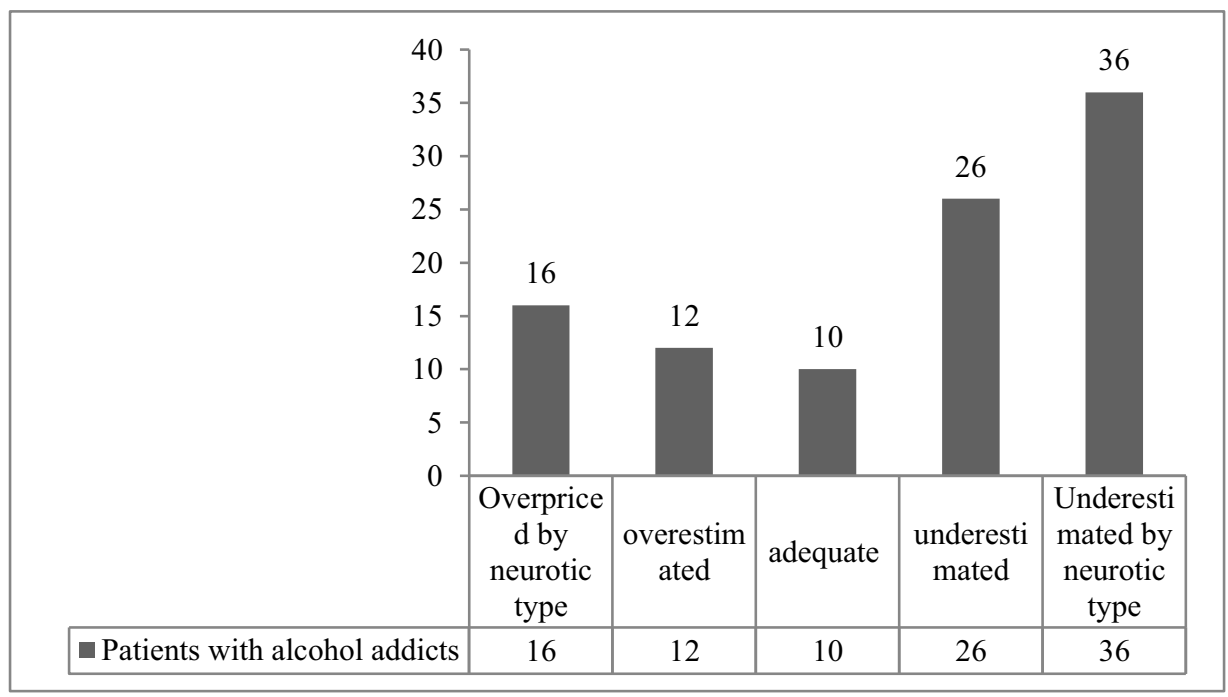

Fig. 1. Results of research of the addicts' self-esteem (\%).

Thus, most patients have low or too low self-esteem levels, which corresponds to the data of other researchers $[27,28]$.

The study of the dynamics of the change of the of self-esteem levels division after four weeks in the experimental group showed that there was a decrease in the number of patients with neurotically too high and neurotically too low, as well as with adequately too low selfesteem and an increase in the number of patients with adequate self-esteem, but the dynamics of these indicators in the experimental group of patients with alcoholism was not significant $(p>0.05)$. Differences in groups were analyzed using the Fischer angular transformation criterion (Table 1).

In the control group, after 4 weeks of rehabilitation, the number of patients with too low and too high self-esteem by neurotic type and with adequately too high self-esteem did not 
change, but the number of patients with adequately low self-esteem increased and the number of people who have adequate self-esteem decreased.

As well as in the experimental group, in the control group of patients with alcohol addiction after 4 weeks of rehabilitation, the dynamics of self-esteem levels are not significant $(\mathrm{p}>0.05)$. This indicates that short-term art therapy in self-esteem correction in alcohol-addictive patients is not effective.

After 8 weeks of art therapy in the experimental patient group, the number of individuals with too high self-esteem by neurotic type $(\mathrm{p} \leq 0.01)$ and the number of patients with neurotically low self-esteem $(\mathrm{p} \leq 0.01)$ decreased significantly. The number of patients with an adequate level of self-esteem $(\mathrm{p} \leq 0.01)$ increased noticeably. Before art therapy, the proportion of patients with alcoholism with adequate self-esteem was only $8 \%$, then after 8 weeks of study it increased to $52 \%$. The results indicate that long-term art therapy is effective in correcting self-esteem in alcohol-addictive patients.

Table 1. Results of the distribution of self-esteem levels in the experimental and control groups at the initial stage of the study and at subsequent measurements (Fischer test).

\begin{tabular}{|l|c|c|c|c|}
\hline \multirow{2}{*}{ Self-esteem level } & \multicolumn{2}{|c|}{$\begin{array}{c}\text { After 4 weeks from the } \\
\text { beginning of the rehabilitation } \\
\text { program }\end{array}$} & $\begin{array}{c}\text { After 8 weeks from the } \\
\text { beginning of the rehabilitation } \\
\text { program }\end{array}$ \\
\cline { 2 - 5 } & $\begin{array}{c}\text { Experimental } \\
\text { group }\end{array}$ & Control group & $\begin{array}{c}\text { Experimental } \\
\text { group }\end{array}$ & $\begin{array}{c}\text { Control } \\
\text { group }\end{array}$ \\
\hline $\begin{array}{l}\text { Overstated } \\
\text { neurotic type }\end{array}$ & 0.820 & 0 & $4.596^{* *}$ & 0.820 \\
\hline Overestimated & 0 & 0 & 0 & 0.940 \\
\hline Adequate & 0.940 & 0.940 & $7.333^{* *}$ & 0.820 \\
\hline Underestimated & 0.643 & 0.643 & 1.329 & 0.643 \\
\hline $\begin{array}{l}\text { Underestimated by } \\
\text { neurotic type }\end{array}$ & 0.622 & 0 & $3.507^{* *}$ & 1.174 \\
\hline
\end{tabular}

Significant differences: ${ }^{*} \mathrm{p} \leq 0.05,{ }^{* *} \mathrm{p} \leq 0.1$.

In the control group of patients suffering from alcoholism, the number of patients with neurotically underestimated self-esteem still did not change, and the dynamics of other levels of self-esteem and after 8 weeks of rehabilitation without the use of art therapy is insignificant $(\mathrm{p}>0.05)$.

The results obtained in the control and experimental groups of patients with alcohol addiction make it possible to talk not only about the effectiveness of art therapy in correcting self-esteem, but also about the necessity to use it.

The analysis of the dynamics of indices of strong-willed self-control, forms of aggression was based on ANOVA analysis of variance with regular repeated measurements, and the effect of the observed changes for each group was assessed using Post Hoc Tests.

The results of the analysis of the indices dynamics of strong-willed self-control, as well as indicators and forms of aggression in the investigating groups at the initial stage of the experiment, after 4 and after 8 weeks are presented in Table 2.

Variance analysis showed that a reliable increase in perseverance, as the ability to finish the started work and achieve the set goals, was observed only after 8 weeks $(p \leq 0.05)$.

It was revealed that in case of the correction of self-control, as the ability to regulate emotional states, short-term art therapy is not effective, while a reliable increase of this ability was observed at least 8 weeks later after the start of the rehabilitation program $(p \leq 0.05)$. There is a positive significant dynamic $(\mathrm{p} \leq 0.05)$ in the decrease of the indicator of physical and verbal aggression of patients with alcoholism already 4 weeks later after the start of art therapy classes. 
Table 2. Differences in indicators of strong-willed self-control and aggression of experimental and control groups at different stages of the study.

\begin{tabular}{|c|c|c|c|c|c|c|}
\hline \multirow{3}{*}{ Variables } & \multicolumn{6}{|c|}{$\begin{array}{c}\text { Results of variance analysis of study scores in a combined sample of } \\
\text { patients with chemical addicts }\end{array}$} \\
\hline & \multicolumn{2}{|c|}{ Primary research } & \multicolumn{2}{|c|}{$\begin{array}{l}\text { After } 4 \text { weeks from the } \\
\text { beginning of the } \\
\text { rehabilitation program }\end{array}$} & \multicolumn{2}{|c|}{$\begin{array}{l}\text { After } 8 \text { weeks from the } \\
\text { beginning of the } \\
\text { rehabilitation program }\end{array}$} \\
\hline & $\mathbf{F}$ & p-level & $\mathbf{F}$ & p-level & $\mathbf{F}$ & p-level \\
\hline \multicolumn{7}{|c|}{ Indicators of strong-willed self-control } \\
\hline Persistence & 2.483 & 0.065608 & 1.804 & 0.151702 & 11.223 & $0.000002 *$ \\
\hline Self-control & 0.809 & 0.491926 & 0.230 & 0.875019 & 17.681 & $0.000000^{*}$ \\
\hline \multicolumn{7}{|c|}{ Indicators and forms of aggression } \\
\hline $\begin{array}{l}\text { Physical } \\
\text { aggression }\end{array}$ & 3.875 & 0.051623 & 3.683 & $0.014745^{*}$ & 6.218 & $0.000672 *$ \\
\hline Indirect aggression & 0.932 & 0.428594 & 0.637 & 0.493332 & 2.979 & 0.065403 \\
\hline Irritation & 0.661 & 0.577941 & 2.144 & 0.099909 & 15.542 & $0.000000^{*}$ \\
\hline Negativism & 2.603 & 0.056512 & 1.683 & 0.175951 & 10.238 & $0.000007^{*}$ \\
\hline Offense & 1.881 & 0.138151 & 1.965 & 0.124505 & 7.962 & $0.000087^{*}$ \\
\hline Suspiciousness & 0.321 & 0.810324 & 0.541 & 0.655149 & 12.081 & $0.000001^{*}$ \\
\hline Verbal aggression & 0.595 & 0.620011 & 0.256 & $0.046651^{*}$ & 8.433 & $0.000051^{*}$ \\
\hline Sense of guilt & 0.185 & 0.906161 & 1.653 & 0.182420 & 11.180 & $0.000002 *$ \\
\hline
\end{tabular}

*Significant.

The indicators of indirect aggression did not change significantly even by the end of the program. Speaking about the other indicators studied, their dynamics in the experimental group significantly changes only by 8 weeks of the rehabilitation program $(p>0.05)$. Thus, during the correction of self-esteem, the general indicator of will control, perseverance, manifestations and forms of aggressiveness (the exception is manifestations of indirect aggression), art therapy methods are effective for alcohol addictive patients, provided that a course duration is at least 8 weeks.

\section{Discussion}

The results of the analysis of the dynamics of indicators of strong-willed control, self-esteem and manifestations of aggression showed that the rehabilitation program using art therapy methods contributes to increasing perseverance, self-control and the general indicator of strong-willed control, forming adequate self-esteem and reducing most forms of aggressiveness and hostility in patients with alcohol addiction. The results we obtained correspond to the data obtained by other researchers. The results demonstrated by Aletraris L. et al. [13] proved the benefits of art therapy in dealing with addicted patients, indicating its effects such as reducing addiction denial, reducing resistance and increasing motivation to treat alcoholism, stimulating and improving communication, encouraging patients to change, taking them away from thinking into a state of action. The data obtained in our research are consistent with the results of the works of Holt E.S. and Kaiser D. H. [15], which showed that the use of art therapy methods in the treatment of addictions increases motivation and creates conditions for internal changes of the client, forms a resource base for recovery. Thus, Zentsova N. I. [29] after applying the art therapy model in the rehabilitation of patients with drug and alcohol addiction, received lower indicators of suspicion and higher indicators of self-regulation of emotions and strong-willed control in experimental groups. Bocharova 
A. S. revealed that art-therapeutic classes contribute to strengthening of self-control of addicts [30]. According to observations by Hanes M. [31], in the process of art therapy, selfesteem and self-confidence increase in patients with chemical addictions. Schmanke L. claims that visual art therapy increases self-esteem in patients with chemical addictions, but no empirical results are given to consider the essential duration of such therapy to achieve a significant effect [32]. The possibility of correcting aggressive manifestations by art therapy methods is particularly often indicated by authors conducting studies on people of primary school and adolescence [33, 34], regarding the effectiveness of art therapy in correcting aggressive manifestations in adults, empirical data are not enough [35]. As for the program's insolvency with regard to the correction of indirect aggression, it should be noted that the development and improvement of indirect aggression is linked to the increasing complexity of social skills [36]. Indirect aggression often becomes a privileged strategy of behavior, characterized by high stability, determined by the growth of verbal and social skills in the process of personality formation [37].

\section{Conclusion}

In conclusion, a gap in the study of the problem of rehabilitation of patients with chemical addictions was filled. It was proved that in order to obtain a statistically reliable effect from the rehabilitation program using art therapy methods in the correction of self-esteem, strongwilled control, indicators and forms of aggression, in addition to indicators of verbal and physical aggression, its duration must be at least 8 weeks. This can be explained by both the difficulty of forming positive personality qualities in adults and their remarkable disorders due to the abuse of psychoactive substances.

\section{References}

1. Fedotov, A. A.: Economics and business: theory and practice (9-2), 123-128 (2020) DOI: 10.24411/2411-0450-2020-10742

2. Hoffmann, A. G.: Clinical Narcology. Medical News Agency, Moscow (2017).

3. Kozhinova, T. A.: Social and clinical psychiatry 28 (3), 46-55 (2018)

4. Berezin, S.V.: Psychology of drug dependence and co-dependence: monograph. IPA, Moscow (2008).

5. Korolenko, Ts. P., Dmitrieva, N.V.: Psychosocial addictology. Olsib, Novosibirsk (2010).

6. B.S Bratus, Psychological analysis of personality changes in alcoholism (Moscow, 2016)

7. Zentsova, N.I., Mubarakova, K. V.: Theory and practice of social development 17, 212 215 (2015).

8. Semenova, E. A., Kharin, V. V., Chernova M.S.: Applied information aspects of medicine 23(1), 73-84 (2020).

9. Boiko, Yu. P.: Medicus 3 (9), 103-104 (2016).

10. Sampedro-Piquero, P. et al.: Neuroscience \& Biobehavioral Reviews 106, 23-48 (2019) https://doi.org/10.1016/j.neubiorev.2018.11.015.

11. Sikora, M. et al.: Behavioural brain research 341, 109-113 (2018) https://doi.org/10.1016/j.bbr.2017.12.027.

12. Wang, D. et al.: PloS one 9(10), e110728 https://doi.org/10.1371/journal.pone.0110728. 
13. Aletraris L. et al.: Journal of addictions nursing 25(4), 190 (2014) https://doi.org/10.1097/jan.0000000000000048.

14. Witkiewitz, K. et al.: Substance use \& misuse 49 (5), 513-524 (2014) https://doi.org/10.3109/10826084.2014.891845.

15. Holt, E.S.: The Arts in Psychotherapy 36(4), 245-250 (2009) https://doi.org/10.1016/j.aip.2009.05.004.

16. Kopytin, A.I.: Art therapy of drug addiction. Treatment, rehabilitation, postrehabilitation. Publishing House of the Institute of Psychotherapy, Moscow (2008).

17. Artyukhina, N.V.: Psychological support of personality development by means of art therapy: methodological manual. Odessa National University named after I. I. Mechnikov, Odessa (2015).

18. Sharp, M.: Expressive Therapies Capstone Theses 30, 1-40 (2018).

19. Platonova, A.V.: Innovative science 12(4), 195-197 (2016).

20. Skirtach, I., Pokul, E.: E3S Web of Conferences (210), 17003 (2020) https://doi.org/10.1051/e3sconf/202021017003

21. Skirtach, I., Denisova, E., Korkhova, V.: E3S Web of Conferences (210), 17007 (2020) https://doi.org/10.1051/e3sconf/202021017007

22. Skirtach, I., Klimova, N., Dunayev A., Korkhova, V.: SHS Web of Conferences (70), 09009 (2019) https://doi.org/10.1051/shsconf/20197009011

23. Martynyuk, Yu. O.: Modern therapy in psychiatry and neurology 1, 9-14 (2017).

24. Suroedova, E., Uvarova, G., Shevkieva, N.: E3S Web of Conferences (210),19005 (2020) https://doi.org/10.1051/e3sconf/202021019005

25. Kiseleva, M.V.: Art therapy in practical psychology and social work. Rech, St. Petersburg (2017).

26. Skuratovskaya, M., Romanova, E.: E3S Web of Conferences. EDP Sciences (210), 18096 (2020) https://doi.org/10.1051/e3sconf/202021018096

27. Ermyakina, N. A.: Bulletin of the Siberian Law Institute of the Ministry of Internal Affairs of Russia 1(30), 48-55 (2018).

28. Vostrikov, V.V.: Psychopharmacology and biological narcology 6 (1-2), 1220-1225 (2016).

29. Dudko, T. N., Zentsova, N. I., Umanova, O. V., Mubarakova, K. V.: Questions of narcology 3, 113-119 (2015).

30. Bocharova, A. S.: Humanitarian scientific research 8, 112-114 (2015).

31. Hanes, M.: Art Therapy 34(4), 201-208 https://doi.org/10.1080/07421656.2017.1394124.

32. Schmanke, L.: Art therapy and substance abuse: Enabling recovery from alcohol and other drug addiction. Jessica Kingsley Publishers, London. Philadelphia (2017).

33. Kurmanova, A. M., Rivera, A. I.: Science and education: problems and prospects-2018, 124-126 (2018).

34. Abramova, L. V.: Topical problems of psychological support of professional and educational and professional activities, 146-149 (2019).

35. Lukyanenko, M., Isahakyan, O.: SHS Web of Conferences 70, 01010 (2019) https://doi.org/10.1051/shsconf/20197001010.

36. Kosonogov, V.V., Vorobyeva, E.V., Kovsh, E.M., Ermakov, P.N.: (IJCRSEE) International Journal of Cognitive Research in Science, Engineering and Education 7(1), 
137-142 (2019) doi: 10.5937/ijcrsee1901137K.

37. Kuznetsova, S.O., Abramova, A. A.: Suicidology 2(2(3)), 15-18 (2011). 